\title{
A Model Experiment for De-astringency of Persimmon Fruit with High Carbon Dioxide Treatment: in vitro Gelation of Kaki-tannin by Reacting with Acetaldehyde
}

\author{
Tomoaki MATSUo and Saburo Itoo \\ Department of Horticulture, Kagoshima University, \\ Korimoto, Kagoshima 890, Japan
}

Received July 3, 1981

\begin{abstract}
In order to explain the mechanism for removing the astringency from persimmon fruit by high carbon dioxide treatment, we studied in vitro whether purified kaki-tannin, a kind of polymeric proanthocyanidin, reacts with acetaldehyde to become a gel under mild conditions or not.

Kaki-tannin reacted with acetaldehyde in a relatively short time to become a gel in phosphate buffer at $\mathrm{pH} 6$ to 8 . Phosphate, malate and citrate accelerated the gel formation, whereas ethanol, ascorbate and Tricine buffer prevented it. Formaldehyde was more effective, and propylaldehyde was less effective than acetaldehyde in causing gelation.

We suggest that the de-astringency is due to the insolubilization of kaki-tannin, which occurs by means of reacting with acetaldehyde produced in the fruit during high carbon dioxide treatment.
\end{abstract}

Japanese persimmon fruit, such as cv. "Hiratanenashi" and "Yokono," has remarkable astringency even at a mature stage, so it is only edible after removal of the astringency by some treatments or as a dried fruit. ${ }^{1)}$ We have studied the de-astringency of persimmon fruit with high carbon dioxide and have reported on an improved method which produced nonastringent fruit of excellent quality. ${ }^{2)}$ This method also provided proof of the important role of acetaldehyde which was produced in the flesh during the carbon dioxide treatment. ${ }^{3)}$ This importance has been further supported by the following findings; i) in a normal atmosphere, an application of dinitrophenol or arsenic trioxide to astringent persimmon fruit induced the insolubilization of kaki-tannin ${ }^{4}$ (it caused remarkable astringency of the fruit). The insobubilization was examined by the "tannin print" method using $\mathrm{FeCl}_{3}$-impregnated filter paper. ${ }^{3,5)}$ It was described by Beevers ${ }^{6)}$ in 1961 that dinitrophenol and arsenic trioxide caused a high accumulation of acetaldehyde in plant tissues without other anaerobic treatment. ii) Soluble tannin in fruit heated in a boiling water bath for an appropriate time was converted to an insoluble form by the application of formaldehyde or acetaldehyde vapor, but not of ethanol vapor. ${ }^{4,7)}$

On the other hand, kaki-tannin was recently explained to be a kind of polymeric proanthocyanidin. ${ }^{8)}$ There have been few reports on the chemical properties of proanthocyanidins. Therefore, to study the mechanism of de-astringency we have investigated the mechanism of the insolubilization and gelation of kaki-tannin during the carbon dioxide treatment.

The experiments presented here investigated whether acetaldehyde reacts with kaki-tannin in vitro under a mild physiological condition to form a gel (i.e. to cause its insolubilization) and examined several factors influencing the rate of gelation and gel toughness.

\section{MATERIALS AND METHODS}

Young persimmon fruits (Diospyros kaki Linn., cv. "Hiratanenashi" and "Jiro") were harvested from July to August in 1980, at the Toso Orchard of Kagoshima University, and cv. "Yokono" and "Fuyu" at the Kihoku 
Branch of the Wakayama Fruit Tree Experimental Station. They were very young fruit and the average fruit weight was about 20 to $30 \mathrm{~g}$.

Kaki-tannin was prepared from the fruit of each cultivar by the same procedure which has been described in detail in a previous paper. ${ }^{9)}$ The aqueous kaki-tannin solution for the gelation experiments was usually adjusted to about 1.5 to $2.0 \%$ of the tannin content, being determined by the Folin-Ciocalteu method ${ }^{10)}$ using (+)-catechin as a standard for the tannin. This concentration of kaki-tannin was convenient for various operations and storing and allowed us to observe the gelation processes at a proper rate.

Acetaldehyde (a special grade for biochemical experiments) was used for the gelation of kaki-tannin and was purchased from Merck Co. Trimethylacetaldehyde was purchased from Aldrich Chem., Co. and (+)-catechin, a standard for the tannin determination was purchased from Sigma, Co. MES and Tricine, for Good's buffer, were purchased from Nakarai Chem., Ltd. All other chemicals were purchased from Wako Pure Chem., Ind. Ltd.

The rate of gelation and the gel point were observed by monitoring the increase in viscosity and in optical density (O.D.) at $610 \mathrm{~nm}$. The measurement of viscosity of the kaki-tannin solution during gelation was carried out using a B-8 $\mathrm{H}$ type viscosimeter with a BL rotor (at 2.5 or 10 rpm, Tokyo Keiki Seizosho, Co., Ltd.).

\section{RESULTS}

\section{Increase in viscosity and turbidity during gelation}

As a preliminary experiment, the purified kaki-tannin (ca. 1.7\%) was incubated in a phosphate buffer ( $\mathrm{pH}$ 6.5) containing acetaldehyde at $25^{\circ} \mathrm{C}$. The gelation process of the reaction mixture was observed by measuring the increase in viscosity and turbidity. The results are shown in Fig. 1. Within 20 min after the reaction had started, a slight turbidity could be detected without any increase in viscosity. An abrupt increase in viscosity was observed at $80 \mathrm{~min}$ and at the same time the turbidity continued to increase in an arithmetic progression. The solution was transformed into a flexible and tough gel at 120 min after the incubation started.

From these results, it was thought that observation of the increase in O.D. at $610 \mathrm{~nm}$ during gelation was more useful than measurement of the increase in viscosity for investigating the gelation process of kaki-tannin. Therefore, the former O.D. observation was

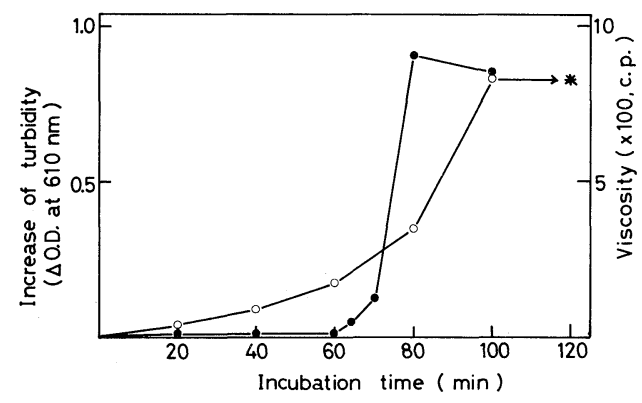

FIG. 1. Changes of Turbidity and Viscosity during Gelation of Kaki-tannin by Reacting with Acetaldehyde. The reaction mixture, consisting of kaki-tannin $(1.47 \%$, $\mathrm{w} / \mathrm{v})$, acetaldehyde $(0.98 \%, \mathrm{w} / \mathrm{v})$ and phosphate buffer $(30 \mathrm{~mm}, \mathrm{pH} 6.5)$, was incubated at $25^{\circ} \mathrm{C}$. The turbidity of the solution was examined as the increase in O.D. at $610 \mathrm{~nm}(-\mathrm{O}-)$ ) and the increase in viscosity (- - ) was measured by a viscosimeter. An asterisk indicates the point when a completed gel was recognized with the naked eye.

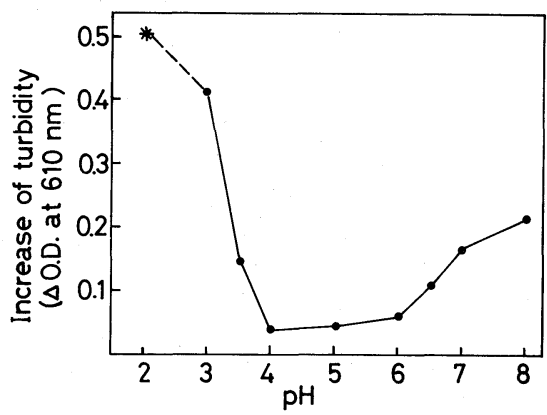

FIG. 2. Effect of $\mathrm{pH}$ on Gelation of Kaki-tannin by Reacting with Acetaldehyde.

The reaction mixture, consisting of kaki-tannin $(1.15 \%$, $\mathrm{w} / \mathrm{v})$, acetaldehyde $(0.98 \%, \mathrm{w} / \mathrm{v})$ and phosphate buffer ( $30 \mathrm{~mm}, \mathrm{pH}$ ranging from 2.0 to 8.0 ), was incubated at $25^{\circ} \mathrm{C}$. A tough gel resulted within $1 \mathrm{hr}$ at $\mathrm{pH} 2.0$. An asterisk indicates the point when a completed gel was recognized with the naked eye.

applied to analyse the gelation phenomenon.

\section{Effect of $\mathrm{pH}$ on gelation}

The rate of gelation of kaki-tannin by reacting with acetaldehyde was definitely influenced by the $\mathrm{pH}$ of the incubation medium, in this case, the phosphate buffer. Figure 2 shows the increase of turbidity in $1 \mathrm{hr}$, when the kakitannin $(58.5 \mathrm{mg})$ was incubated at $25^{\circ} \mathrm{C}$ in $4 \mathrm{ml}$ of phosphate buffer (finally $30 \mathrm{~mm}$ ), $\mathrm{pH}$ rang- 
ing from 2.0 to 8.0 , containing $39.4 \mathrm{mg}$ of acetaldehyde. At and below $\mathrm{pH} 3.5$, rapid turbidity was observed and tough gel resulted for a short time, especially at $\mathrm{pH} 2.0$ within $1 \mathrm{hr}$. The gelation reaction, which showed a minimum rate at $\mathrm{pH} 4$ and 5 , was stimulated in the range from $\mathrm{pH} 6$ to 8 . The rate of gelation at $\mathrm{pH} 7.0$ was nearly the same as it was at $\mathrm{pH}$ 3.5. At and over $\mathrm{pH} \mathrm{6.0,} \mathrm{the} \mathrm{resulting} \mathrm{gel} \mathrm{had} \mathrm{a}$ slightly brown color and as time elapsed the brown color became more gradually intense. At the more acidic $\mathrm{pH}$ the gel remained creamy or white in color.

\section{Effect of acetaldehyde content on gelation}

Figure 3 shows how the content of acetaldehyde influences the rate of gelation under the conditions of a given kaki-tannin content and buffer concentration $(1.1 \%, 30 \mathrm{~mm}, \mathrm{pH}$ 6.5). The rate of increase in turbidity was very dependent on the acetaldehyde content. The reaction mixture with a ratio of kaki-tannin to acetaldehyde of about $1: 1(\mathrm{w} / \mathrm{w})$ showed a striking increase in turbidity soon after the reaction started and was transformed into a gel after $3 \mathrm{hr}$ incubation at $25^{\circ} \mathrm{C}$. At one-half of this amount of acetaldehyde in the reaction mixture it required $5 \mathrm{hr}$ to change the solution

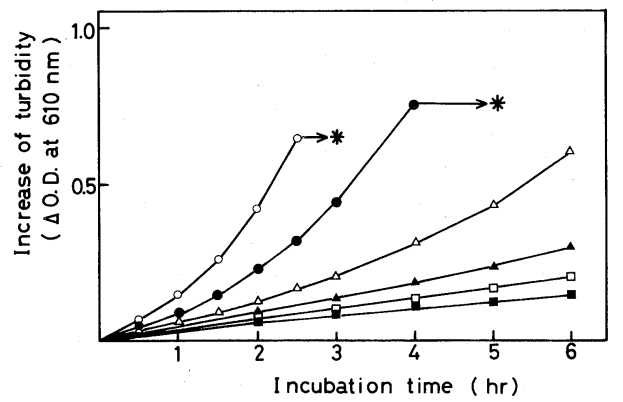

FIG. 3. Effect of Acetaldehyde Content on Gelation of Kaki-tannin.

Each incubation mixture $(4 \mathrm{ml})$ contained kaki-tannin $(42 \mathrm{mg}$ ), acetaldehyde (the content ranging from $0.8 \mathrm{mg}$ to $39.4 \mathrm{mg}$ ) and phosphate buffer ( $30 \mathrm{~mm}, \mathrm{pH} 6.5)$. The incubation was carried out at $25^{\circ} \mathrm{C}$ in a sealed test tube and cell. The measurement was done as shown in Figs. 1 and $2 . \bigcirc, 39.9 \mathrm{mg}$ of acetaldehyde; $\bigcirc, 19.7 \mathrm{mg}, \triangle, 7.9 \mathrm{mg}$; $\boldsymbol{\Delta}, 3.9 \mathrm{mg} ; \square, 1.9 \mathrm{mg} ; \boldsymbol{\square}, 0.8 \mathrm{mg}$. into a gel. Four days after the reaction started, the reaction mixture with a ratio of about 50 to 1, kaki-tannin to acetaldehyde, became fairly turbid but not a gel. At a low content of acetaldehyde the gel formed was relatively soft.

\section{Effect of molar concentration of phosphate buf- fer on gelation}

The effect on gelation of the molar concentration of the phosphate buffer was examined at $\mathrm{pH} 6.5$ in the same reaction mixture as Fig. 3. The results showed that in spite of the addition of a sufficient amount of acetaldehyde, the concentration of the phosphate buffer strongly influenced the rate of gel formation and the increase in turbidity (Fig. 4).

The reaction mixtures containing $300 \mathrm{~mm}$ and $120 \mathrm{~mm}$ of phosphate buffer became turbid at almost the same rate and formed a gel at $1.5 \mathrm{hr}$ and $2 \mathrm{hr}$ of incubation respectively. The reaction mixture containing the $30 \mathrm{~mm}$ phosphate buffer formed a gel after $3 \mathrm{hr}$ and in the $6 \mathrm{~mm}$ phosphate buffer, gel formation was recognized after $19 \mathrm{hr}$. The gel resulting in the reaction mixture containing $6 \mathrm{~mm}$ phosphate buffer was transparent. Within $24 \mathrm{hr}$ the reaction mixture without the phosphate buffer showed a slight turbidity.

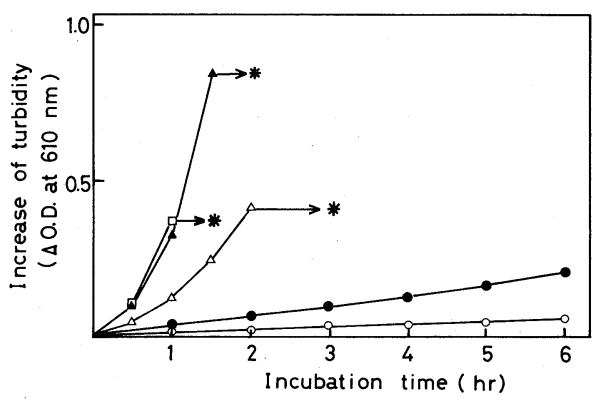

FIG. 4. Effect of Molar Concentration of Phosphate Buffer on Gelation of Kaki-tannin by Reacting with Acetaldehyde.

The reaction mixture consisted of kaki-tannin $(1.15 \%$, $\mathrm{w} / \mathrm{v})$, acetaldehyde $(0.98 \%, \mathrm{w} / \mathrm{v})$ and phosphate buffer (the molar concentration ranging 0 to $300 \mathrm{~mm}$, at $\mathrm{pH} 6.5$ ). See Figs. 1, 2 and 3 for details. $\square, 300 \mathrm{~mm} \boldsymbol{\Delta}, 120 \mathrm{~mm} ; \triangle$, $30 \mathrm{~mm}$; , $6 \mathrm{~mm} ; \bigcirc, 0 \mathrm{~mm}$, only $\mathrm{H}_{2} \mathrm{O}$. 


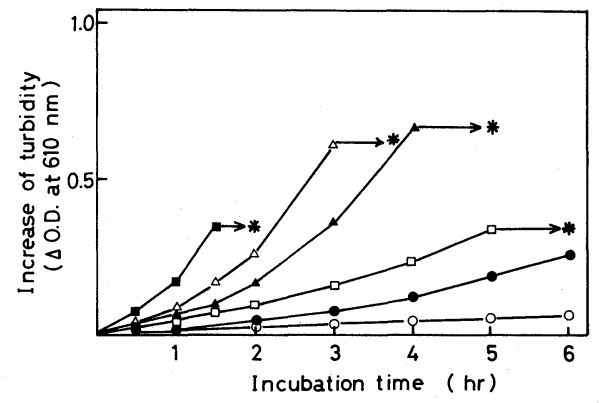

FIG. 5. Effect of Buffer Constituents on Gelation of Kaki-tannin by Reacting with Acetaldehyde.

The reaction mixture contained kaki-tannin $(1.15 \%, \mathrm{w} / \mathrm{v})$, acetaldehyde $(0.98 \%, \mathrm{w} / \mathrm{v})$ and $30 \mathrm{~mm}$ buffer having different constituents. See Figs. 1, 2 and 3 for details.

$\mathrm{Na}_{2} \mathrm{HPO}_{4}-\mathrm{H}_{3} \mathrm{PO}_{4}$ and $\mathrm{Na}_{2} \mathrm{HPO}_{4}$-citric acid buffer at $\mathrm{pH}$ $7.0 ; \triangle$, citrate at $\mathrm{pH} 6.0 ; \Delta$, phosphate at $\mathrm{pH} 6.0 ; \square$, $\mathrm{MES}-\mathrm{NaOH}$ at $\mathrm{pH} 7.0$;, Tris- $\mathrm{AcOH}$ at $\mathrm{pH} 7.1 ; 0$, Tricine- $\mathrm{NaOH}$ at $\mathrm{pH} 7.4$.

\section{Effect of buffer constituents on gelation}

Changes in the increase of turbidity caused by different buffer constituents were examined in the next experiment at a given molar concentration $(30 \mathrm{~mm})$. The rate of increase in turbidity accompanied by gel formation was considerably different in each buffer system (Fig. 5). At pH 7.0, the buffers $\mathrm{Na}_{2} \mathrm{HPO}_{4}-$ $\mathrm{H}_{3} \mathrm{PO}_{4}$ and $\mathrm{Na}_{2} \mathrm{HPO}_{4}$-citric acid had the same rate of increase in turbidity and formed a gel at $2 \mathrm{hr}$ of incubation. The citrate buffer ( $\mathrm{pH} \mathrm{6.0)}$ stimulated formation of the gel more rapidly than the phosphate buffer with the same $\mathrm{pH}$. The gelation of kaki-tannin was accelerated less in the buffer of MES-NaOH ( $\mathrm{pH} \mathrm{7.0)} \mathrm{or}$ Tris-acetate $(\mathrm{pH} \mathrm{7.1)}$ than in the former buffers. No detectable increase of turbidity was observed within $24 \mathrm{hr}$ in the reaction mixture consisting of Tricine--NaOH buffer ( $\mathrm{pH} 7.4)$.

\section{Reactivities of several aldehydes with kaki- tannin}

Some aldehydes having a proton(s) at the $\alpha$ position, other than acetaldehyde, caused gel formation of kaki-tannin under a mild condition (30 mm phosphate buffer, $\mathrm{pH} \mathrm{6.5,} \mathrm{at}$ $25^{\circ} \mathrm{C}$ ), as shown in Fig. 6. Formaldehyde caused an extremely rapid gelation within 30 min. Propylaldehyde, having an extra meth-

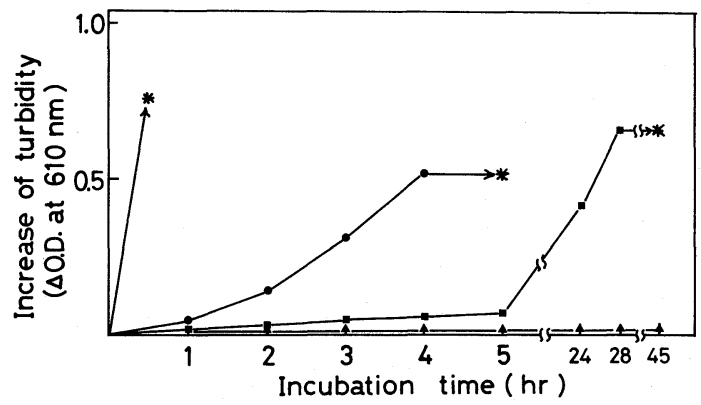

FIG. 6. Reactivities of Several Aldehydes with Kakitannin in the Phosphate Buffer at pH 6.5.

The reaction and measurement were carried out as in Figs. 2 and 3. $\longrightarrow *$, formaldehyde ; - - , acetaldehyde; $-\mathbf{\square}-$, propylaldehyde; - - -, trimethylacetaldehyde. The incubation mixture contained the same amount of each aldehyde $(39.4 \mathrm{mg} / 4 \mathrm{ml})$.

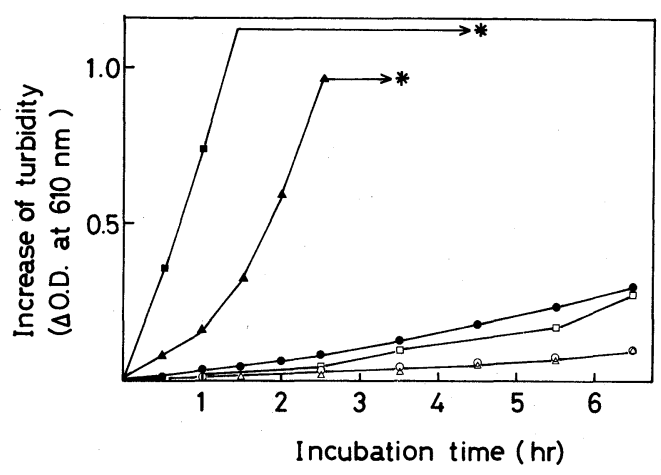

FIG. 7. Effect of Several Additives on Gelation of Kakitannin by Reacting with Acetaldehyde.

Each concentration of several additives was $100 \mathrm{~mm}$, except $12 \%$ of ethanol and $29.6 \mathrm{~mm}$ of dimedone. The reaction and measurement were carried out as in Figs. 2 and 3. $\boldsymbol{\sim}, \mathrm{NaCl} ; \boldsymbol{\Delta}, \mathrm{Na}_{2}$ malate; $\boldsymbol{O}$, glucose and buffer only; $\square, \mathrm{CaCl}_{2} ; \mathrm{O}, \mathrm{EtOH} ; \triangle, \mathrm{Na}$ ascorbate and dimedone.

ylene group than acetaldehyde, required more time to make a gel, at $45 \mathrm{hr}$ of incubation. Trimethylacetaldehyde, having no proton at the $\alpha$-position, did not induce gelation of kaki-tannin. Even after 7 days, an increase in turbidity was not detected from the increase in O.D. at $610 \mathrm{~nm}$.

\section{Effect of several additives on gelation}

The influence of several additives to the reaction medium on the gelation of kakitannin was examined. Glucose (100 mM) 
showed no effect on the acceleration of gelation but the same amount of sodium malate strongly stimulated it and the reaction medium transformed into a gel after 3.5 hr (Fig. 7). On the other hand, ethanol (12\%), sodium ascorbate $(100 \mathrm{~mm})$ and dimedone $(29.6 \mathrm{~mm})$ prevented the reaction. The reaction mixture containing $12 \%$ ethanol resulted in a soft gel after 2 days, but the mixture containing sodium ascorbate and dimedone did not result in turbidity and a gel even after 7 days. Salting-out predominated the acceleration of gelation in the action of sodium chloride $(100 \mathrm{~mm})$. The solution resulted in a white precipitate for a short time and thereafter formed a gel at about $4.5 \mathrm{hr}$ after the reaction started.

\section{Reactivities of three kinds of kaki-tannin with} acetaldehyde

It is important to know whether kaki-tannin prepared from the non-astringent type fruit transformed into a gel after adding acetaldehyde in the same manner as that from the astringent type fruit, cv. "Hiratanenashi." Kaki-tannins prepared from cv. "Fuyu," nonastringent type and from cv. "Yokono," astringent type fruits formed turbidity at the same rate and in similar manner, as shown in Fig. 8. "Fuyu"-tannin became a gel more rapidly than the other two kaki-tannins which

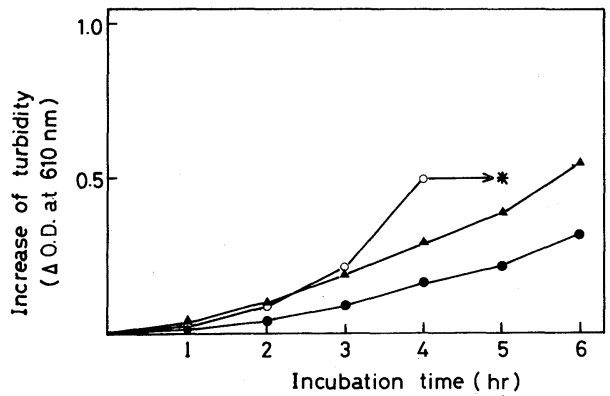

FIG. 8. Reactivities of Three Kinds of Kaki-tannin with Acetaldehyde.

The reaction and measurement were carried out as in Figs. 2 and 3. The tannin concentration of each medium is; Fuyu; $1.12 \%$, Yokono; $0.95 \%$, Hiratanenashi; $1.15 \%$. $\bigcirc$, Fuyu-tannin; $\boldsymbol{\Delta}$, Yokono-tannin; O, Hiratanenashitannin. were prepared from two kinds of astringent fruits. All of them transformed into a gel within $8 \mathrm{hr}$, at about the same tannin concentration (Hiratanenashi; 1.15\%, Yokono; $0.93 \%$, Fuyu; $1.12 \%$ ).

\section{DISCUSSION}

The present work on de-astringency was carried out in vitro, in contrast with all the other works which were done in vivo. We examined whether the purified kaki-tannin could react with acetaldehyde to form a gel under a mild condition, a physiological condition. It has been known for a long time that large amounts of acetaldehyde accumulated in the flesh of persimmon fruit when deastringency was completed by some treatments, e.g. high carbon dioxide, ${ }^{11 \sim 14)}$ ethanol $^{11,12)}$ and warm water. ${ }^{7,15)}$

At $\mathrm{pH} 6$ to 7, a physiological $\mathrm{pH}$ presumed generally as the $\mathrm{pH}$ of plant cells, kaki-tannin easily bacame a gel by reacting with acetaldehyde (in the weight ratio of about 1 to 1 ), as shown in Figs. 1 and 2. The reaction was strongly dependent upon the $\mathrm{pH}$ of the medium and the minimum rate was recognized between $\mathrm{pH} 4$ and 5 (Fig. 2). This finding was consistent with the report described by Hills and $\mathrm{Urbach}^{16)}$ in that the reaction of phloroglucinol or the A-ring of catechin with the relatively weak electrophilic aldehydes was slowest at $\mathrm{pH} 4.5$.

In considering the function of acetaldehyde on de-astringency, it is interesting that the other kinds of aldehydes behave very differently in their reaction with kaki-tannin, as shown in Fig. 6. The fast reaction of formaldehyde, the slow reaction of propylaldehyde and the non-reaction of trimethylacetaldehyde suggest that the reaction between kaki-tannin and acetaldehyde contains a "condensation reaction." It is probably a reaction similar to phenol-formaldehyde condensation known popularly in polymer chemistry. We have already explained kaki-tannin to be a kind of polymeric proanthocyanidin. ${ }^{8)}$

Singleton and $\mathrm{Esau}^{17)}$ stated that during 
wine aging, phenols and anthocyanin might react with acetaldehyde to form a haze and precipitate. Some of the polyphenols in wine are found to be low molecular weight flavonoids and procyanidins. ${ }^{18)}$ Similarly, the addition of formaldehyde to the mash prior to the brewing of beer produced a great reduction in the tendency of the beer to form a haze by precipitating anthocyanogens. ${ }^{19,20)}$

An important problem remains obscure: whether the insolubilization of kaki-tannin in vivo is responsible for the formation of a gel in the tannin cells. There is some evidence in regard to this point.

Gazit and Levy, ${ }^{21)}$ Kitagawa, ${ }^{22}$ and Yoshimura and Kusumoto ${ }^{23)}$ illustrated a tannin cell filled with insoluble tannin in fruits from which the astringency was removed by some treatments. We also observed that the isolated tannin cells prepared by using cellulase and Macerozyme were transparent and colorless which looked to be filled with a gellike substance. Kitagawa ${ }^{24)}$ described that the tannin cells in the non-astringent fruit were broken and cracked like glass when he crushed them beneath a cover glass.

The insoluble tannin in the non-astringent cells was observed to be transparent and colorless, as described above. The present experiment showed that at a high buffer concentration a turbid gel was formed but at a lower concentration clear gel formed. It seems that the ion concentration may be relatively low in the central vacuoles of tannin cells.

The fundamental change in the tannins leading to insolubility and the mechanism initiating this change is suggested by these findings that the kaki-tannin transforms into a gel by reacting with the acetaldehyde produced by the fruit cells under high carbon dioxide. At least, it can be evidently concluded that it has a character which reacts easily with acetaldehyde in the presence of some acids, such as phosphate, malate or citrate (Figs. 4, 5 and 7).

The importance of acetaldehyde has further been supported by the following results.

Kitagawa $^{24)}$ tried to confirm it through a unique experiment. He boiled some immature fruits to inactivate all the enzymes but some quantity of tannin remained in a soluble form. When the fruits were then treated with ethanol, methanol or acetaldehyde, only the acetaldehyde effectively caused insolubilization of the residual soluble tannin and removed the astringency. We have also ascertained the importance from a similar experiment in vivo. ${ }^{4)}$

Figure 3 shows that at least more than $2 \%$ of acetaldehyde for a given amount of kakitannin is essential for gelation. In this experiment the concentration of kaki-tannin was $1.15 \%$, while the persimmon fruit has an average 1.5 to $2.0 \%$ tannin..$^{1)}$ Thus the content of kaki-tannin in the tannin cells is assumed to be around $6.0 \%$ on the fresh weight basis. If it is correct, the kaki-tannin in these cells may become a gel more easily at a lower acetaldehyde content. This may be the amount of acetaldehyde which the persimmon fruit can produce itself under such a de-astringency treatment. Nakamura ${ }^{12)}$ reported that $8.3 \mathrm{mg} \%$ of acetaldehyde accumulated in the flesh after completing de-astringency by a high carbon dioxide treatment ( 7 days at about $20^{\circ} \mathrm{C}$ ).

The striking fall in astringency during the growth and maturing on non-astringent type fruits of persimmon can be observed and they are edible as fresh fruits without any treatment. ${ }^{1)}$

Figure 8 shows that "Fuyu"-tannin forms turbidity at the same rate and in similar manner to "Yokono"- and "Hiratanenashi"tannin. Whether "Fuyu"-tannin has a chemical tendency to become a gel more rapidly is obscure. It is generally known among persimmon producers that the "Yokono" fruit is one which dose not easily become completely non-astringent after the common treatments. Figure 8 showed evidence that "Yokono"tannin reacted with acetaldehyde more easily than "Hiratanenashi"-tannin. The difference between both tannins is not known to be physiologically significant at the present time. It appears to be very important to investigate the derivation of the difference in the reaction 
with acetaldehyde. New information is needed from a further in vivo examination of this point.

Acknowledgments. We are indebted to Dr. M. A. Austin (Coastal Plain Experiment Station, University of Georgia) and Dr. S. Iwahori (Department of Horticulture, Kagoshima University) for valuable suggestions during the preparation of this manuscript, and $\mathrm{Mr}$. M. Ogawa (Wakayama Fruit Tree Experimental Station, Wakayama Prefecture) for a generous supply of "Fuyu" and "Yokono" fruits of persimmon. This work was supported in part by a Grant-in-Aid for Scientific Research (No. 576024) from the Ministry of Education, Science and Culture of Japan.

\section{REFERENCES}

1) S. Itoo, "Tropical and Subtropical Fruits," ed. by S. Nagy and P. E. Shaw, AVI Publishing, Connecticut, 1980 , p. 442.

2) T. Matsuo and S. Itoo, Agric. Biol. Chem., 40, 215 (1976).

3) T. Matsuo and S. Itoo, Plant and Cell Physiol., 18, 17 (1977).

4) T. Matsuo and S. Itoo, in preparation.

5) I. L. Eaks, Proc. Am. Soc. Hort. Sci., 91, 868 (1967).

6) H. Beevers, "Respiratory Metabolism in Plants," ed. by H. Beevers, Row-Peterson Biological Monographs, 1961, p. 232.

7) H. Kitagawa, J. Jpn. Soc. Hort. Sci., 37, 379 (1969).

8) T. Matsuo and S. Itoo, Agric. Biol. Chem., 42, 1637
(1978).

9) T. Matsuo and S. Itoo, Agric. Biol. Chem., 45, 1885 (1981).

10) V. L. Singleton and J. A. Rossi, Jr., Am. J. Enol. Viticult., 16, 144 (1965).

11) C. Araki, K. Kaneko and T. Aketagawa, J. Jpn. Soc. Hort. Sci., 44, 183 (1975).

12) R. Nakamura, Nippon Shokuhin Kogyo Gakkaishi (J. Jpn. Soc. Food and Tech.), 20, 529 (1973).

13) T. Tarutani and M. Manabe, Tech. Bull. Fac. Agric. Kagawa Univ., 8, 233 (1957).

14) I. Tazaki and C. Matsuoka, Nogaku Kaiho (J. Jpn. Soc. Agric. Sci.), 256, 113 (1924).

15) K. Kakeshita, Nogyo to Engei (Agric. and Hort.), 5, 1151 (1930).

16) W. E. Hillis and G. Urbach, J. Appl. Chem., 9, 474 (1959).

17) V. L. Singleton and P. Esau, "Adv. Food Res.," Suppl. 1, Academic Press, N. Y. and London, 1969, p. 1.

18) E. Haslam, Phytochemistry, 19, 2577 (1980).

19) A. Macey, K. C. Stowell and H. B. White, J. Inst. Brew. (London), 72, 29 (1965).

20) A. J. Whatling, J. Pasfield and D. E. Briggs, J. Inst. Brew. (London), 74, 525 (1968).

21) S. Gazit and Y. Levy, Israel J. Agric. Res., 13, 125 (1963).

22) H. Kitagawa, J. Jpn. Soc. Hort. Sci., 37, 89 (1968).

23) F. Yoshimura and S. Kusumoto, Research Rep. Kochi Univ., Agric. Sci., 23, 65 (1974).

24) H. Kitagawa, "Kaki no Saibai to Riyo (The Cultures and Processings of Persimmon Fruits)," ed. by H. Kitagawa, Yokendo Press, Tokyo, 1970, p. 182. 